\title{
Pemberdayaan Kader Usaha Kesehatan Sekolah (UKS) Melalui Pembinaan UKS di SDN I Kalirejo Kabupaten Banyuwangi
}

\author{
Elita Endah Mawarni \\ Program Studi D3 Keperawatan STIKES Banyuwangi \\ Email : litaendah36@gmailcom
}

\begin{abstract}
SDN I Kalirejo is one of the elementary schools that has many students and it is potential to become a cadre of School Health Unit which is expected to support the sustainability of School Health Unit. This school is no less feasible when compared to other elementary schools in Banyuwangi. From the observations result, the implementation of School Health Unit has not been optimal because of human resources and infrastructure facilities that have not been utilized properly and continuously. To support the continuity and sustainability of School Health Unit program and activities at Kalirejo I Elementary School, guidance and counseling are badly needed in the form of giving skills and health knowledge from competent mentor or counselor, so it is expected to increase the knowledge from the health sectors for local school residents and it will improve their health level automatically.
\end{abstract}

Keywords : Empowerment, School Health Unit, improve their health

\section{Pendahuluan}

Usaha Kesehatan Sekolah atau UKS adalah upaya pendidikan dan kesehatan yang dilaksanakan secara terpadu, sadar, berencana, terarah, dan bertanggung jawab dalam menanamkan, menumbuhkan, mengembangkan, dan membimbing untuk menghayati, menyenangi, dan melaksanakan prinsip hidup sehat dalam kehidupan peserta didik sehari-hari. ${ }^{1}$ Upaya peningkatan derajat kesehatan siswa tentunya harus dirumuskan tentang tujuan dari pelaksanaan Usaha Kesehatan Sekolah (UKS) yang ingin dicapai. Tujuan Umum dari UKS adalah meningkatkan mutu pendidikan dan prestasi belajar peserta didik dengan meningkatkan perilaku hidup bersih dan sehat serta derajat kesehatan peserta didik maupun warga belajar, dan menciptakan

${ }^{1}$ Ahmad Selvia . Seri Pengetahuan UKS. Sidoarjo: Masmedia Buana Pustaka. 2009:1 
lingkungan sehat, sehingga memungkinkan pertumbuhan dan perkembangan yang harmonis dan optimal dalam rangka pembentukan manusia Indonesia Seutuhnya. ${ }^{2}$ SDN I Kalirejo berada di lingkungan Kecamatan Kabat, wilayah ini terletak di sebelah selatan, bersebelahan langsung dengan Kecamatan Banyuwangi. SDN I Kalirejo Banyuwangi berdiri dan beroperasi sejak tahun 1957 dengan luas wilayah keseluruhan mencapai $4000 \mathrm{~m}^{2}$ serta luas Bangunan 408 m2 dengan Sertifikat Hak Milik ( SMH ). Dengan jumlah siswa keseluruhan pada tahun 2019 sebanyak 232 orang dan jumlah tenaga pendidik dan pegawai sebanyak 11 orang.

Permasalahan yang ada di SDN I Kalirejo adalah Program UKS di SDN I Kalirejo, sebenarnya sudah ada sejak lama, namun dari hasil observasi yang dilakukan, pelaksanaannya belum optimal. Dilihat dari SDM dan sarana yang sudah ada belum dimanfaatkan dengan baik dan kontinyu. Dengan kegiatan pembinaan dan penyuluhan berupa ketrampilan dan pengetahuan kesehatan dari pihak yang berkompeten diharapkan dapat menambah wawasan dari sektor kesehatan untuk warga sekolah setempat yang secara otomatis taraf kesehatan mereka pun menjadi lebih meningkat. Untuk keberlangsungan kegiatan UKS, kader kesehatan dipandang perlu menyusun health program sebagai media publikasi yang bersifat transparan, dapat dipertanggung jawabkan dan bersinergis dalam menyelenggarakan program-program, baik itu oleh Dinas kesehatan terhadap kelompok akademis secara vertikal dan kader kesehatan terhadap pemenuhan tingkat kebutuhan warga sekolah dari segi kesehatan menyeluruh secara horisontal.

\section{Metode}

Program ini merupakan program yang bersifat aktual dalam rangka peningkatan pengetahuan dan wawasan kader kesehatan di SDN I Kalirejo, Desa Kalirejo, Kecamatan Kabat tentang trias UKS dengan langkah sosialisasi

${ }^{2}$ Kementerian Kesehatan. Pedoman Akselerasi Pembinaan dan Pelaksana UKS , 2016: 3 
dan pelatihan. Untuk kepentingan pencapaian tujuan program ini, maka rancangan yang dipandang sesuai untuk dikembangkan adalah "RRA dan PRA" (rural rapid appraisal dan Participant rapid appraisal). Di dalam pelaksanaannya, program ini akan mengacu pada pola sinergis antara tenaga pakar dan praktisi dari STIKES Banyuwangi dengan kalangan birokrasi dan kalangan akademisi SDN I Kalirejo, Desa Kalirejo, Kecamatan Kabat. Di sisi lain, program ini juga diarahkan pada terciptanya iklim kerjasama yang kolaboratif dan demokratis dalam dimensi mutualis antara dunia perguruan tinggi dengan masyarakat secara luas di bawah koordinasi akademisi setempat, khususnya dalam rangka peningkatan pengetahuan dan wawasan kader kesehatan SDN I Kalirejo, Desa Kalirejo, Kecamatan Kabatsecara cepat namun berkualitas bagi kepentingan pembangunan akademisi setempat. Berdasarkan rasional tersebut, maka program ini merupakan sebuah langkah inovatif dalam kaitannya dengan Tri Dharma perguruan tinggi, yaitu salah satunya adalah pengabdian kepada masyarakat.

Kegiatan Pengabdian masyarakat dilaksanakan selama 1 (satu) hari, dimulai dari jam 09.00 WIB sampai dengan selesai. Tempat pelaksanaan kegiatan di SDN 1 Kalirejo, Desa Kalirejo, Kecamatan Kabat, Kabupaten Banyuwangi, Propinsi Jawa Timur.

\section{Hasil dan Diskusi}

Program ini dirancang sebagai bentuk jawaban dari permasalahan belum tersedianya sumber daya manusia yang potensial dalam mengolah dan melaksanakan kegiatan UKS sebagai jenis usaha yang dapat dikembangkan dalam meningkatkan derajat kesehatan bagi warga sekolah setempat. Dengan pelaksanaan program yang sifatnya rintisan ini dirancang sosialisasi dan pelatihan bagi kader kesehatan dengan materi pelatihan, diantaranya yaitu trias UKS terutama mengenai perilaku hidup sehat dan gizi seimbang. Model pelaksanaan kegiatan dilakukan secara langsung (tatap muka) 
sebagaimana layaknya temu wicara antara tim pelaksana dan peserta kegiatan yaitu kader kesehatan.

Lama pelaksanaan kegiatan adalah 1 (satu) hari yang dimulai dari tahap perencanaan, pelaksanaan sampai pada proses evaluasi dengan melibatkan seluruh kader kesehatan yang ada di SDN I Kalirejo, Desa Kalirejo, Kecamatan Kabat. Melalui program ini, diharapkan kader kesehatan yang ada di SDN I Kalirejo, Desa Kalirejo, Kecamatan Kabatmendapatkan pengetahuan dan pemahaman yang jelas tentang trias UKS terutama mengenai perilaku hidup sehat dan gizi seimbang serta luaran yang diperoleh dari hasil pelatihan dan sosialisasi bagi kader kesehatan yang ada di SDN I Kalirejo, Desa Kalirejo, Kecamatan Kabat, secara kontinyuitas peserta yang tergabung dalam kegiatan pelatihan dan sosialisasi diharapkan dapat menjadi bekal wawasan pengetahuan, ketrampilan dengan mau menyebarluaskannya pada seluruh siswa yang ada di SDN I Kalirejo, Desa Kalirejo, Kecamatan Kabat.

Realisasi Pelaksanaan Program

Setelah melalui proses pendekatan, maka kami perlu menyusun program sebagai berikut :

1. Mencari informasi terkait masalah SDM dalam mendukung pelaksanaan Usaha Kesehatan Sekolah. Dari sini bisa diperoleh informasi bahwa siswa SDN I Kalirejo yang menjadi kader UKS memiliki pengetahuan dasar tentang kesehatan khususnya tentang PHBS dan gizi seimbang.

2. Mengajak mereka untuk bekerjasama dalam pengembangan dan pelaksanaan UKS

3. Memberikan pengarahan melalui sosialisasi penguatan SDM kader UKS 
a. Pembentukan kelompok kader UKS

Dari hasil observasi dan pendekatan kepada kader UKS, perlu adanya tindak lanjut dari kegiatan tersebut,seperti pembentukan kelompok SDM dalam pelaksanaan program UKS.

b. Proses sosialisasi dan pengarahan materi PHBS dan Gizi seimbang

1) Perilaku Hidup Bersih Sehat (PHBS)

Perilaku Hidup Bersih Sehat (PHBS) adalah semua perilaku kesehatan yang dilakukan karena kesadaran pribadi sehingga keluarga dan seluruh anggotanya mampu menolong diri sendiri pada bidang kesehatan serta memiliki peran aktif dalam aktivitas masyarakat. PHBS di sekolah merupakan kegiatan memberdayakan siswa,guru dan masyarakat lingkungan sekolah untuk mau melakukan pola hidup sehat untuk menciptakan sekolah sehat. Manfaat PHBS di Sekolah mampu menciptakan lingkungan yang bersih dan sehat, meningkatkan proses belajar mengajar dan para siswa, guru hingga masyarakat lingkungan sekolah menjadi sehat.

Contoh PHBS di sekolah

a) Mencuci tangan dengan sabun sebelum dan sesudah makan,

b) Mengkonsumsi jajanan sehat,

c) Menggunakan jamban bersih dan sehat

d) Olahraga yang teratur

e) Memberantas jentik nyamuk

f) Tidak merokok di lingkungan sekolah

g) Membuang sampah pada tempatnya, dan

h) Melakukan kerja bakti bersama warga lingkungan sekolah untuk menciptakan lingkungan yang sehat. 


\section{2) Gizi Seimbang}

Gizi seimbang adalah susunan makanan sehari-hari yang mengandung zat gizi dalam jenis dan jumlah yang sesuai dengan kebutuhan tubuh, dengan memerhatikan prinsip keanekaragaman atau variasi makanan, aktivitas fisik, kebersihan, dan berat badan (BB) ideal.

Untuk membantu setiap orang memilih makanan dengan jenis dan jumlah yang tepat, kebutuhan asupan gizi divisualisasikan dalam bentuk Tumpeng Gizi Seimbang (TGS), yang terdiri atas potongan-potongan tumpeng. Luasnya potongan menunjukkan porsi yang harus dikonsumsi setiap hari. TGS dialasi air putih, artinya air putih merupakan bagian terbesar dari zat gizi esensial bagi kehidupan untuk hidup sehat dan aktif.

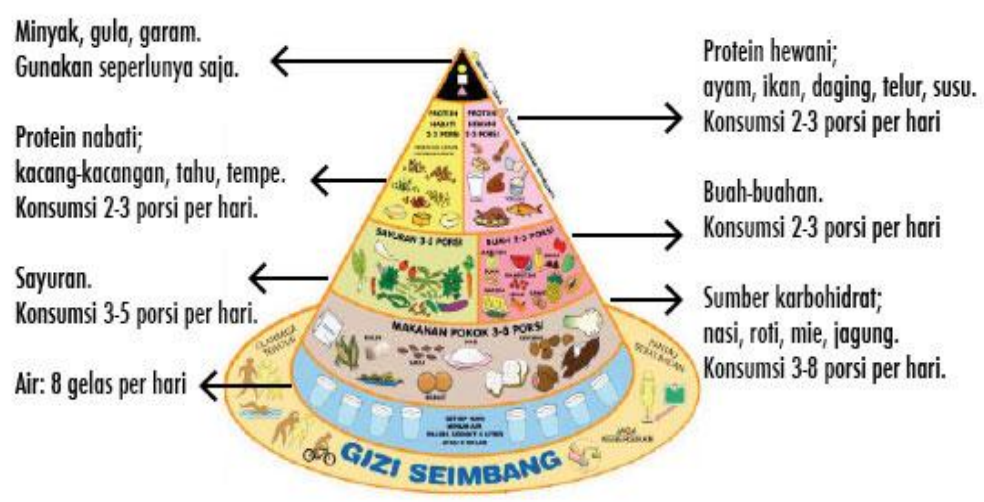

Gambar 1. Tumpeng Gizi Seimbang (TGS)

(Sumber: Dokumentasi, 2019)

Pada bagian bawah tumpeng terdapat prinsip gizi seimbang yang lain, seperti manjalankan pola hidup bersih, aktivitas fisik dan olahraga teratur serta senantiasa menjaga dan memantau berat badan. 


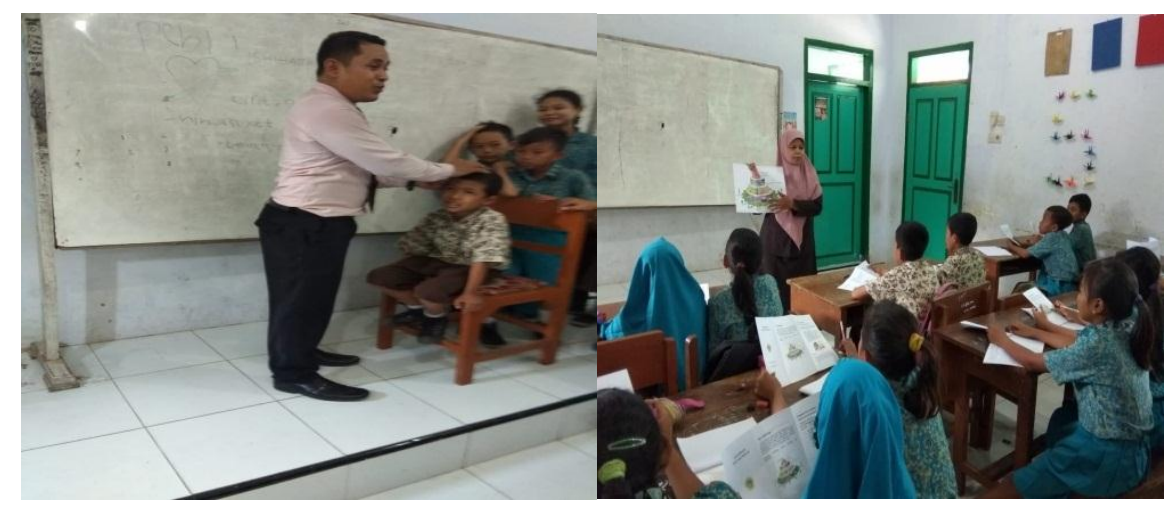

Gambar 2. Proses pelaksanaan sosialisasi dan pengarahan kader UKS dengan tema PHBS dan Gizi Seimbang

(Sumber: Dokumentasi, 2019)

\section{Evaluasi Pelaksanaan Program}

Untuk mengukur tingkat keberhasilan yang telah dilakukan, maka akan dilakukan evaluasi minimal 3 (tiga) kali, yaitu evaluasi proses, akhir, dan tindak lanjut. Kegiatan evaluasi ini akan melibatkan tutor/pakar dari STIKES Banyuwangi.

Kriteria dan indikator pencapaian tujuan dan tolak ukur yang digunakan untuk menjustifikasi tingkat keberhasilan kegiatan dapat diuraikan pada tabel berikut :

Tabel 1. Indikator Keberhasilan Program Pengabdian masyarakat UKS

\begin{tabular}{|c|c|c|c|c|c|}
\hline No & Jenis Data & Sumber Data & Indikator & $\begin{array}{c}\text { Kriteria } \\
\text { Keberhasilan }\end{array}$ & Instrumen \\
\hline 1 & $\begin{array}{l}\text { Pengetahuan } \\
\text { tentang trias UKS } \\
\text { terutama } \\
\text { mengenai PHBS } \\
\text { dan Gizi } \\
\text { Seimbang }\end{array}$ & $\begin{array}{l}\text { kader } \\
\text { kesehatan } \\
\text { yang ada di } \\
\text { SDN I } \\
\text { Kalirejo, Desa } \\
\text { Kalirejo, } \\
\text { Kecamatan } \\
\text { Kabat } \\
\text { Kabupaten } \\
\text { Banyuwangi }\end{array}$ & $\begin{array}{l}\text { Pengetahuan } \\
\text { kader } \\
\text { kesehatan yang } \\
\text { ada di SDN I } \\
\text { Kalirejo, Desa } \\
\text { Kalirejo, } \\
\text { Kecamatan } \\
\text { KabatKabupate } \\
\text { n Banyuwangi } \\
\text { tentang trias } \\
\text { UKS terutama } \\
\text { mengenai } \\
\text { PHBS dan Gizi } \\
\text { Seimbang }\end{array}$ & $\begin{array}{l}\text { Terjadi } \\
\text { perubahan } \\
\text { yang positif } \\
\text { terhadap } \\
\text { pengetahuan } \\
\text { trias UKS } \\
\text { terutama } \\
\text { mengenai } \\
\text { PHBS dan Gizi } \\
\text { Seimbang }\end{array}$ & $\begin{array}{l}\text { 1. Praktek } \\
\text { PHBS } \\
\text { 2. Presentasi } \\
\text { dengan } \\
\text { tema Gizi } \\
\text { seimbang }\end{array}$ \\
\hline
\end{tabular}

Sumber: Dokumentasi, 2019

Pemberdayaan Kader Usaha Kesehatan Sekolah (UKS) Melalui Pembinaan UKS di SDN I Kalirejo Kabupaten Banyuwangi 
Keseluruhan proses transfer iptek ini dilaksanakan dengan pola sosialisasi dan pelatihan terhadap kader kesehatan yang ada di SDN I Kalirejo, Desa Kalirejo, Kecamatan KabatKabupaten Banyuwangi yang meliputi: Pengetahuan tentang trias UKS terutama mengenai PHBS dan Gizi Seimbang.

Hasil dari kegiatan sosilisasi dan pelatihan yang kami lakukan adalah terbentuknya kader-kader UKS di SDN I Kalirejo, Desa Kalirejo, Kecamatan Kabat Kabupaten Banyuwangi yang memiliki penguasaan pengetahuan dan ketrampilan lebih tentang PHBS dan Gizi Seimbang. Mereka juga temotivasi untuk melakukan program tersebut secara berkesinambungan dan dapat meningkatkan derajat kesehatan anggotanya.

Kendala dan Solusi selama Pelaksanaan Program

1) Kendala sebelum terlaksananya program

a) Perilaku hidup bersih dan sehat dan gizi seimbang belum mencapai tingkat yang diharapkan.

b) Masalah sumber daya manusia.

c) Masih belum optimalnya koordinasi antar instansi terkait dalam menangani UKS.

2) Solusi setelah terlaksananya progrm

a) Mengadakan sosialisasi dan pelatihan kepada kader UKS SDN I Kalirejo, mengenai Perilaku Hidup Bersih Sehat (PHBS) dan gizi seimbang, supaya terbentuknya perilaku sehat dimanapun berada terutama di lingkungan sekolah.

b) Mengadakan sosialisasi dan pelatihan kepada kader UKS SDN I Kalirejo, mengenai penguatan sumber daya manusia supaya terbentuknya kelompok pelaksana program UKS.

c) Merencanakan kerjasama antara pihak sekolah dengan instansi terkait dalam mendukung keberlnjutan pelaksanaan UKS. 


\section{Simpulan}

SDN I Kalirejo merupakan sekolah dasar yang terletak di Desa Kalirejo, Kecamatan Kabat, Kabupaten Banyuwangi yang sudah terbentuk kader UKS namun pelaksanaannya belum optimal. Kurangnya tenaga pendamping dalam pelaksanaan UKS di SDN I Kalirejo, dan minimnya kegiatan sosialisasi/pembinaan dari instansi terkait mengakibatkan pelaksanaan program ini belum optimal. Fasilitas dan lokasi belajar yang terpisah menjadi 2 lokasi menyulitkan untuk mengadakan koordinasi secara langsung antar kader UKS, guru pendamping, serta anggota UKS.

Dalam upaya mendukung keberlangsungan pelaksanaan program UKS secara kontinyu di SDN I Kalirejo, kami melaksanakan sosialisasi/pembinaan program UKS yang mendapat dukungan dari pihak sekolah serta para kader UKS. Dari kegiatan ini terbentuklah kader UKS "plus" yang mendapat pengetahuan dan ketrampilan tambahan terutama tentang materi PHBS dan Gizi Seimbang serta mau mentransfer ilmu yang diperoleh ke anggota UKS lainnya. Dan dari situ juga terbentuklah kader UKS yang siap mendukung keberlangsungan pelaksanaan program UKS secara kontinyu.

Dari pembahasan diatas dapat diambil kesimpulan bahwa UKS adalah program kesehatan di sekolah pada umumnya dan di SDN I Kalirejo khususnya, karena minimnya kegiatan sosialisasi/pembinaan dari instansi terkait mengakibatkan pelaksanaan program ini belum optimal. Sehingga perlu adanya sosialisasi/pembinaan bagi kader UKS, agar pelaksanaan program tersebut bisa berjalan secara aktif dan membawa manfaat bagi sekolah.

\section{Rekomendasi}

Hasil pelaksanaan pembinaan UKS di SDN I Kalirejo ini, maka kami merekomendasikan kepada pihak sekolah serta siswa terutama dalam hal ini kader UKS, bahwasanya perlu adanya tindak lanjut program yang dilaksanakan. Terbentuknya kader UKS dan adanya pembinaan yang sudah dilakukan hanya sekali dari instansi terkait belum cukup dalam mengatasi 
masalah yang ada, akan tetapi diperlukan pendampingan/pembinaan secara kontinyu agar program yang sudah terbentuk bisa berjalan dengan baik. Deengan adanya rekomendasi ini diharapkan program bisa berjalan secara kontinyu dan bisa bermanfaat bagi sekolah, serta pelaksanaan UKS di SDN I Kalirejo tetap terlaksana dengan baik dan bisa menjadi ciri khusus atau unggulan SDN I Kalirejo.

\section{Referensi}

Departemen Kesehatan. (2008). Pedoman Pelatihan Kader Kesehatan di Sekolah. Jakarta: Departemen Kesehatan

Depkes RI. (2008) Petunjuk Teknis Standar Pelayanan Minimal Bidang Kesehatan di Kabupaten/Kota. http://bankdata.depkes.go.id

Endah, Elita. (2015). Pendidikan Kesehatan Makanan Sehat untuk Anak Sekolah, Laporan Program Pengabdian Masyarakat, Banyuwangi : Program Studi D3 Keperawatan STIKES Banyuwangi

Kementerian Kesehatan. (2016). Pedoman Akselerasi Pembinaan dan Pelaksana UKS. http://kesga.kemkes.go.id/images/pedoman/pedoman\%20aksel\%20 UKS-2016.pdf.

Mubarak, Wahid Iqbal \& Chayatin, Nurul. (2009), ilmu kesehatan masyarakat : teori dan aplikasi, Jakarta : Salemba Medika

Notoatmojo, Soekijo, 2007. Kesehatan Masyarakat Ilmu dan seni. Rineka Cipta Selvia, Ahmad. (2009). Seri Pengetahuan UKS. Sidoarjo: Masmedia Buana Pustaka

Sumantri, M. (2007). Pendidikan Wanita. Dalam Ali, M., Ibrahim, R., Sukmadinata, N.S. dan Rasjidin, W. (Penyunting). Ilmu dan Aplikasi Pendidikan: Handbook. Bandung: Pedagogiana Press (Halaman 1175 1186). 